\title{
An Investigation into the Institutional Response of South African Public Universities to HIVIAIDS
}

\author{
Jack Chokwe \\ English Studies \\ chokwmi@unisa.ac.za \\ Lynette Naidoo \\ Phathizwe Manana \\ Blessing Mbatha \\ Department of Communication Science \\ Suwisa Muchengetwa \\ Department of Statistics
}

Doi:10.5901/mjss.2013.v4n13p727

\begin{abstract}
The HIVIAIDS infection rate in South Africa is one of the highest in the world. The article reports on the study that sought to determine the supportive role played by South African public universities in combating the spread of HIVIAIDS. The diffusion of innovation theory underpinned this study. A qualitative approach was adopted and semi-structured interviews were conducted with universities' clinic staff and/or HIVIAIDS staff and those involved in the formulation of the HIVIAIDS policies and implementation. Though all 23 public universities in South Africa were included in the study, only 15 participated. Data were analysed using open coding and thematic categorisation. The findings show that some South African public universities are already playing a significant role in educating their communities and should continue with their interventions. Results also show that owing to financial and structural constraints, some universities have not fulfilled the Department of Higher Education and Training's mandate.
\end{abstract}

Keywords: public universities, HIVIAIDS, higher education institutions, HIV prevention, intervention programmes

\section{Introduction and background to the study}

The human immunodeficiency virus and acquired immune deficiency syndrome (HIVIAIDS) pandemic has grown to be the greatest public health crisis facing the world since the $13^{\text {th }}$ century (HEAIDS, 2009b). The Higher Education HIVIAIDS Programme (HEAIDS) is a nationally co-ordinated initiative to develop and strengthen the capacity of South Africa's higher education (HE) sector to respond comprehensively to the challenges posed by the HIVIAIDS pandemic and to play a leadership role in the South African HIVIAIDS response. The HIVIAIDS pandemic, a multidimensional human crisis with social, economic, cultural and psychological dimensions, requires a response from all sectors of South African society. This includes $\mathrm{HE}$, which has a fundamental role to play in mitigating and managing the effects of the pandemic through all aspects of its core operations of tuition, research and community engagement.

The Higher Education and Training Ministry in South Africa is concerned with the negative impact that HIVIAIDS has in our society (HEAIDS, 2009b). The ministry believes that an appropriate response to the pandemic entails the adoption of a collective approach in which all relevant role-players work together to mitigate the negative effects of HIVIAIDS in society (HEAIDS, 2009b). This includes continuing to raise awareness about HIVIAIDS, helping to prevent further transmission of the disease, as well as providing support and care for those infected and affected. As primary generators and disseminators of new knowledge in society, higher education institutions (HEls) have the capacity to influence policy and shape the development agenda of the nation by, among other things, steering research into strategic areas such as HIVIAIDS. Through teaching and training, the sector can educate young people about HIVIAIDS and issues of sexuality in general. It is therefore crucial that HE leadership be proactive and plays a central role in the 
fight against HIVIAIDS (Eloff, 2008). The objective of the research reported on in this article was to determine the supportive role played by South African public universities in combating the spread of HIVIAIDS. This research is important to South African university communities, the South African government and researchers in the field of HIVIAIDS.

\section{Problem statement}

The problem emanates from the HIVIAIDS infection rate in South Africa, which is among the highest in the world (UNAIDS, 2010; Vearey, Richter, Núñez, and Moyo, 2011: 382). HIVIAIDS has a direct influence on human resource development, and therefore poses a threat to the future skills and knowledge base of the country. Since universities stand at the forefront of education, they are strategically positioned to be the best social response against the epidemic. The HE sector has a responsibility to inform and empower its communities, including students, who represent future leaders, and staff, who are the valuable human capital responsible for producing knowledge in the country. Both students and staff must therefore be mobilised to become part of the response against HIVIAIDS.

\section{Literature review}

Rugalema and Khanye (2004:87) state that most ministries of education are designing policies and sectoral strategic plans to deal with the problems caused by HIVIAIDS in the education system. In South Africa the Department of Higher Education and Training (DHET) and the 23 public sector HEls adopted a Policy Framework on HIVIAIDS for Higher Education in South Africa. This policy framework is based on three objectives. The first objective is to provide strong, committed, internal (institutional) and external (societal) leadership through the institutions' role of producing graduates, stimulating academic discourse and disseminating new knowledge. The second objective is to create a healthy and safe environment within institutions that is based on ethical principles, legal norms and human rights, while the third objective is to establish a sector response to the impact of HIVIAIDS that is co-ordinated, comprehensive and integrated (HEAIDS, 2009b).

Rugalema and Khanye (2004: 87-88) further argue that the mainstreaming of HIVIAIDS in learning institutions should be based on three fundamental conditions. First, programmes for learners and teachers should be designed to incorporate both curriculum-based and extracurricular programmes (including, but not limited to, edutainment). Second, HIVIAIDS prevention and impact mitigation programmes that focus on education managers and support staff working with educational institutions should be developed. The third condition is the design and sustained operation of a robust management information system pertaining to HIVIAIDS. Policy framework development and utilisation seems to be the first standard approach that institutions employ in creating effective intervention strategies against HIVIAIDS. The Southern African Regional Universities Association (SARUA, 2007) argues that universities must identify key areas requiring prioritisation in policies; these would include prevention, treatment, and care and support activities. This argument is supported by the Higher Education HIVIAIDS Programme (HEAIDS, 2009b; Kareithi and Lund, 2011: 466), in which it is stipulated that each HEI should develop and disseminate a workplace HIVIAIDS or chronic disease policy aligned to relevant national labour legislation and institutional human resources (HR) policies.

HEAIDS (2009a) identifies six institutional performance areas as being critical in the response to the HIVIAIDS pandemic. These include strategic leadership, decision-making and co-ordination; research and analysis; a workplace HIVIAIDS policy; a workplace HIVIAIDS prevention programme; a workplace HIVIAIDS treatment and care strategy; and monitoring and evaluation. These performance areas guided the formulation of the interview guide in the research reported on, and have further been used as the benchmark during the analysis.

SARUA (2007), supported by George and Sprague (2011: 300), states that prevention activities should include HIVIAIDS awareness raising; identifying and changing university practices that encourage high-risk sexual behaviour; distribution of male and female condoms; provision of HIV counselling and testing; treatment of sexually transmitted infections (STIS) and access to reproductive health services. These preventive measures should be adopted in order to counter risk factors such as other STIs; binge drinking, leading to decreased individual responsibility; multiple sexual partners and significant age gaps between sexual partners. Treatment, care and support activities should include access to treatment programmes; HIV testing services; psycho-social support and counselling programmes; information on nutrition and diet; referral services for the diagnosis and treatment of TB; as well as programmes that reduce the stigma of HIV. Where cases of infection arise, information about antiretroviral treatment should be readily available, as should be support in the form of AIDS support clubs, counselling, referral services and the treatment of opportunistic infections. In this context, the diffusion of innovation theory, which is discussed below, was found to be suitable for the research 
because of its relevance to how universities can communicate prevention, care and support ideas effectively to their communities.

The United Nations Educational, Scientific and Cultural Organisation (UNESCO, 2011) argues that information and communication can help fight HIVIAIDS by changing young people's behaviour through preventive education schemes and awareness-raising campaigns. Effective communication can help universities to curb negative factors, seek new means to prevent the spread of HIV, and support those affected and infected. Modern society is characterised by a constant flow of new products and solutions, making the diffusion of innovation theory a suitable theoretical framework in this research. Rogers (2003) states that the diffusion of innovation theory focuses on the communication process by which a new idea or product becomes known and used by people in a given population. Fourie (2007) argues that this theory applies in communication in the innovation of products or ideas and the role of communication in disseminating the innovation, which could take the form of new ideas, fashions and beliefs. The diffusion of innovation theory therefore helps us to consider how universities can communicate effective prevention, care and support ideas effectively to their stakeholder groups.

\section{Research methodology}

A qualitative research method was adopted to determine the role played by public universities in South Africa in fighting the spread of HIVIAIDS. The target population was all 23 public universities in South Africa. A census of the universities was taken; so no sampling was done. All 23 universities were approached to take part in the study so as to ensure fair representation and to gain an insight into their implementation of HIVIAIDS activities and policies. Of the 23 universities, 15 participated, giving a response rate of $65 \%$. The remaining 7 universities had not been granted permission to participate by the time the study was conducted, and were therefore not included. One university was used for the pilot study, and 22 were invited to participate in the actual study. The participants comprised the universities' medical clinic staff and/or HIVIAIDS office and/or those involved in the formulation of the HIVIAIDS policy and its implementation. The participants were selected using purposive sampling and semi-structured interviews were conducted with the key informants. The data was analysed using open coding and thematic categorisation.

\section{Findings and discussions}

The following themes emerged during the open coding process.

\subsection{Action plans for treatment, care and support and their implementation}

Respondents were required to reflect on the action plans emanating from their policies and the implementation of these at their institutions. It was clear from the interviews that the action plans that universities had implemented overlapped. A selection of responses is presented below.

- Our university provides Voluntary Counselling and Testing (VCT) programmes to staff and students.

- We have hired a clinical psychologist to counsel our staff and students.

- We distribute condoms to our students and staff.

- The university has implemented various care and support programmes to cater to the needs of students and staff.

- $\quad$ Some of the interventions that we have implemented include counselling and testing programmes.

- $\quad$ HIVIAIDS awareness campaigns form an integral part of the university's programme of action.

- The edutainment programmes that we find provide on campus are well attended and are an effective means of information dissemination and sensitisation.

- We provide circumcision referrals.

- Abstinence campaigns are one of the key intervention programmes that we offer as part of our response.

- Peer educators have been employed by the university.

- We use a wellness mobile unit to provide health services to the surrounding community base.

- We have a clinic on campus where we deal with various health related issues including HIVIAIDS

- We have an HIVIAIDS course that is compulsory for all our first year students. 
The research established that some universities introduced an HIVIAIDS course into each curriculum that was compulsory for all first-year students. One of the key performance areas as prescribed by HEAIDS (2009a: 30) entails a workplace HIVIAIDS treatment and care strategy. The framework states clearly that each HEl should develop a treatment and care strategy for employees infected with HIV and/or AIDS. This aligns the institutional workplace programmes to both this workplace framework and relevant individual institutional policies, thereby promoting a level of equity and standardisation.

The findings show overlapping of the action plans implemented in South African public universities, which could be attributed to the fact that all universities are guided by the same government strategic plan for combating HIVIAIDS. In addition, HEAIDS has identified the framework for key performance areas to which HEls should adhere in the battle against the pandemic. The framework has six key performance areas that make up a comprehensive workplace programme and sets out key standards for each of the six performance areas as discussed in the literature review. Also, HEAIDS designed a framework implementation guide that HEIs should follow in fighting HIV/AIDS.

This implementation guide has been designed to follow the format of the framework for HIVIAIDS workplace programmes, and it provides practical advice on how to implement each of the key performance areas for HIVIAIDS workplace programmes. This guide is not meant to be prescriptive, but is intended as a tool for use in developing each institution's HIVIAIDS workplace programme (HEAIDS, 2009a: 3). In short, it was found that all the South African public universities that participated in the study had implemented action plans in response to the government mandate to fight the HIVIAIDS pandemic.

\subsection{Availability of resources for the implementation of the action plan}

This theme relates to the resources, such as funding, qualified staff and office space, required to operationalise the action plans of the respective universities. It was clear from the interviews that some universities had no resources, while others had insufficient resources. Some of the universities indicated a lack of funding to run HIVIAIDS programmes. The research further established that in a number of universities office space was problematic, and this resulted in a number of employees in HIVIAIDS units sharing offices. The findings indicated that providing adequate office space was not a priority in certain universities.

Although some universities found the Department of Health to be helpful with regard to providing funding for HIVIAIDS activities, some institutions relied on sponsorships to operationalise these activities. This reliance in certain cases extended to complete dependence on donor funds for carrying out HIVIAIDS activities. Respondents indicated that various NGOs, including NewStart, were supportive of the objective of fighting against the spread of HIVIAIDS. Respondents further noted that the HIVIAIDS units were not fully independent because they were not always able to access university funds for their activities.

\subsection{Management and students' commitment}

One of the objectives of the study was to establish the visible commitment of university management and students to combating HIVIAIDS. This was important in order to ascertain whether all key stakeholders were participating in the fight against the pandemic. The findings showed that although all public universities in South Africa had institutional policies on HIVIAIDS, some of the key stakeholders were not committed to the fight against the spread of the pandemic. For example, it was established during interviews that the management and students of some universities did not participate in important HIVIAIDS events. On a positive and encouraging note, it was found that management at certain universities had introduced postgraduate diplomas in HIVIAIDS. Interpreted in the light of the diffusion of innovation theory, the introduction of postgraduate diplomas by some of the universities surveyed is considered an innovative way of creating awareness as a contribution to curbing the spread of HIVIAIDS.

\subsection{Prevention programmes}

It is important for universities to offer their staff and students prevention programmes, hence the question to respondents regarding the types of HIVIAIDS prevention programmes and services available in their respective universities. Below are some of the interview responses.

- Our institution provides VCT services.

- We distribute condoms on campus and we have peer educators who advise students on HIVIAIDS matters. 
- Various prevention programmes and awareness campaigns have been introduced on campus as part of our response to the pandemic.

- $\quad$ Our university is proudly South African, therefore we invite local celebrities to endorse our awareness campaigns on campus.

- We use edutainment as one of our intervention activities.

- We refer students to hospitals and clinics for circumcisions.

- Our institution carries out abstinence campaigns and this forms an integral part of our programme of action.

- We adopt appropriate prevention and awareness programmes to encourage behavioural change patterns among our students.

It is clear from the responses above that universities had various prevention programmes in place in their response to the HIVIAIDS pandemic. This aligns with the HEAIDS strategic framework (HEAIDS, 2009b: 1), which argues that universities should stand at the forefront in the fight against this pandemic.

\subsection{HIVIAIDS research}

Respondents were asked to comment on the HIVIAIDS research activities that their institutions were involved in, as this was one of the priority areas that universities were mandated with by the DHET. The findings are presented below.

- $\quad$ An HIV centre for research is based at our university.

- We do not have the necessary resources to conduct formal research.

- At our university there is currently a lack of formal research on HIVIAIDS. We engage in collaborative research with other universities.

- $\quad$ Our institution has established strong links with key stakeholders in the health sector in integrating with our research efforts.

- The research we engage in is intersectoral and interdisciplinary thereby ensuring cross-cutting perspectives in the findings.

- We have postgraduate students who are currently conducting HIVIAIDS research, which contributes somewhat to our research outputs in this field.

- There are multi-disciplinary research initiatives driven by our faculty.

- We have a special fund for HIVIAIDS research which we encourage researchers at the university to use.

- The university organises annual HIVIAIDS conferences and symposia.

With regard to research conducted in the area of HIVIAIDS in public universities, the findings showed that in some universities no research was being carried out in this area. Although research is one of the major functions of a higher education institution, the study established that certain universities showed no sense of urgency concerning conducting research in this critical area.

\subsection{Community engagement}

Community engagement is one of the mechanisms a tertiary institution can adopt to mobilise and equip the citizenry regarding issues affecting them. Therefore, respondents were asked to comment on their institutional involvement in community engagement with respect to HIVIAIDS. Responses included the following:

- $\quad$ Our university provides VCT programmes to the broader community.

- We partner with NGOs in support of local communities regarding HIVIAIDS e.g. VCT.

- We provide peer education programmes to our community.

- We provide peer-to-peer education to our community.

- We provide workplace peer education programmes to our community.

- We distribute condoms to our community.

- We partner with local schools where we implement HIVIAIDS awareness campaigns.

- We use a wellness mobile unit to provide health services to our community. 
Responses indicated that universities had introduced a variety of community engagement programmes in the context of HIVIAIDS. However, it is worth noting that some universities for various reasons found it difficult to engage in community outreach programmes. The findings showed that in response to the pandemic a number of universities had embarked on the provision of peer education programmes in their communities. These findings align with the views of Dickinson (2011: 336), who argues that peer education can play a significant role in mobilising and equipping the youth with information about HIVIAIDS. Likewise, Ditekemena, Matendo, Koole, Colebunders, Kashamuka, Tshefu, Kilese, Nanlele and Ryder (2011: 166) emphasise that VCT programmes are essential for curbing the spread of the epidemic. Although they are not completely safe, condoms have been considered the most effective precautionary measure for halting the epidemic; Mbatha (2009: 49), for instance, acknowledges that because they are readily available, condoms have proved to be an effective and widely used measure for preventing HIVIAIDS.

\section{Recommendations}

It is suggested that implementation bottlenecks in the action plan be cleared. Strategies in response to the HIVIAIDS pandemic exist, but implementation has been weak owing to a lack of capacity and resources. In order for institutions to respond to the HIVIAIDS pandemic, sufficient resources are required. With regard to the commitment of management and students to preventing HIVIAIDS, it was established that some universities were fully involved in their response, while others showed apathy and lacked commitment. There is therefore an urgent need for synergistic involvement in fighting the HIVIAIDS pandemic. HEAIDS prescribes that each HEI should develop an integrated prevention response to HIVIAIDS. The findings showed that the degree of implementation of the prevention programmes varied. Therefore, there is an urgent need for all universities to offer their staff and students effective prevention programmes. As vehicles and creators of knowledge in society, higher education institutions have the capacity to shape policy and strategy in core areas such as HIVIAIDS research. By incorporating HIVIAIDS education into the curricula, the sector can equip young people with relevant knowledge to curb the pandemic. It is therefore crucial that higher education institutions be proactive and uses this avenue to play a fundamental role in the fight against HIVI AIDS. There should be more support for the implementation of the universities' action plans as well as closer monitoring and evaluation of the higher education sector's responses to HIV. It is recommended that further research be conducted on how the education sector intends to reduce the gap between knowledge and practice when it comes to social behaviour trends and patterns.

\section{Conclusion}

The aim of the study was to determine the supportive role played by South African public universities in combating the spread of the HIVIAIDS pandemic. A comprehensive plan of action involving meaningful inputs from various sectors of society, including the state, higher education institutions, community leaders, religious organisations and nongovernmental organisations is required. Some universities were found to have introduced action plans, and thus to have responded to the Department of Education's mandate. However, the extent to which these action plans had been implemented varied, and they were not aligned with the HEAIDS framework implementation guide. But, some of the institutions were unable to respond optimally to the HIVIAIDS pandemic because of inadequate resources. The HIVIAIDS pandemic remains a significant threat to global health and prosperity. Halting the spread of the disease in higher education institutions and communities at large and providing life-saving care to those living with HIVIAIDS is one of the government's fundamental goals. If the status quo in terms of fighting the pandemic remains the way it is in higher education institutions, more people will be infected with and affected by the virus, which will have a negative effect on economic and social progress.

\section{References}

Dickinson, D. (2011). Myths, science and stories: working with peer educators to counter HIVIAIDS myths, African Journal of AIDS Research, Vol. 10(3): 335-344.

Ditekemena, J., Matendo, R., Koole, O., Colebunders, R., Kashamuka, M., Tshefu, A., Kilese, N., Nanlele, D., and Ryder, R. (2011). Male partner voluntary counselling and testing associated with the antenatal services in Kinshasa, Democratic Republic of Congo: a randomized controlled trial, International Journal of STD and AIDS, Vol. 22(3): 165-170.

Fourie, P. J. (2007). Media studies: media history, media and society. Cape Town: Juta.

George, G. and Sprague, C. (2011). HIV prevention in the world of work in sub-Saharan Africa: research and practice, African Journal of AIDS Research, Vol. 10(3): 291-300.

HEAIDS (2009a). A guideline to implementing an HIVIAIDS workplace programme. Pretoria. 
HEAIDS (2009b). Development and implementation support for HIVIAIDS workplace programmes at 23 public higher education institutions in South Africa, 2009. Pretoria: Higher Education South Africa.

Kareithi, R. N. M. and Lund, C. (2011). Obstacles to creating an environment conducive to HIV prevention for young people, African Journal of AIDS Research, Vol. 10(4): 465-477.

Mbatha, B. T. (2009). Barriers that impede the effectiveness of precautionary measures of combating the spread of HIVIAIDS: the case of the University of Zululand and Mangosuthu University of Technology, Journal of Human \& Social Sciences, Vol. 1(1): 43-50.

Rogers, E. M. (2003). Diffusion of innovations. New York: Free Press.

Rugalema, G. and Khanye, V. (2004). Mainstreaming HIVIAIDS in the education system in sub-Saharan Africa: some preliminary insights, in C. Coombe (ed.) The HIV challenge to education: a collection of essays (pp 81-103). Paris: IIEP.

SARUA (2007). HIV \& AIDS an action guide for higher education institutions in the SADC region. SARUA.

UNAIDS (2010). Unite for universal access: Overview brochure on 2011 High Level Meeting on AIDS. Available at: http://www.unaids.org/en/aboutunaids/unitednationsdeclarationsandgoals/2011highlevelmeetingonaids/ [Accessed 13/10/2011].

UNESCO (2011). HIVIAIDS. Available at: http://portal.unesco.org/ci/en/ev.php-url id=23984\&url do=do topic\&url section=201.html [Accessed: 14/10/2011.

Vearey, J., Richter, M., Núñez, L. and Moyo, K. (2011). South African HIVIAIDS programming overlooks migration, urban livelihoods, and informal workplaces, African Journal of AIDS Research, Vol. 10(3): 381-391. 
